\title{
Disglobal Basho
}

\author{
ALFREDO ANDIA \\ Florida International University
}

\section{DANA CUPKOVA Carnegie Mellon University}

\section{DISGLOBAL}

The idea for this international conference was conceived around a non-existent word: "disglobal." The word emerged as a reaction to decades of discourse that have relentlessly argued that world is "globalizing." The ideology of globalization claimed that after the conclusion of the cold war international trade took over the world and unleashed an unstoppable process of internationalization of markets and culture.

\section{IS THE WORLD GLOBALIZING?}

Is the world really globalizing? In 1996, Paul Krugman, a rising star in the field of international trade theory in economics published a book called "Pop Internationalism." Krugman argued that most views about the impacts of international trade in the world economy were amateur, distorted, and "a dangerous obsession." He claimed that at the time only $10 \%$ of the world economy was connected to trade and when one did the math the actual economic effect of globalization was marginal. ${ }^{1}$

Twelve years later, in 2008, Paul Krugman won the Nobel Prize in Economics in the field of "international and regional economics" and because of "his analysis of trade patterns and location of economic activity." ${ }^{2}$ By 2016, international trade had risen well above what it was in 1996 but Krugman and other trade economists still believed their models show that trade have had a low contribution to the world's economy. ${ }^{3}$

\section{GLOBALIZED ARCHITECTURE?}

Also the globalization hysteria has swept numerous architectural circles in the West. Some questioning if most contemporary cities are becoming "generic," like the contemporary airport. ${ }^{4}$ However, if one travels to cities and regions like Santiago, Lima, Rio, Barcelona, or Bombay, one can clearly feel with particular strength the indigenous flavor of each location. Moreover one can argue that there is a strong and emerging body of work developed by small ateliers in Latin America, Asia, Africa, and new experimental collectives in the US and Europe that have surfaced from natively grown conditions. I think you should develop here a bit more what is implied - that there is a top down tendency of the global to equalize and the bottom up tendency of the local to disturb the forces of homogenization.

\section{DISGLOBAL CHILE}

In our conference in Santiago we had a great number of examples of these practices in the work of our keynotes speakers: Alejandro Aravena, Mirene Elton, Teresa Moller, Mauricio Pezo and Sofia Von Ellrihshausen, and Cazu Zegers. All of these practices are part of a larger and robust number of architectural offices that have emerged in the country of Chile and whose work is highly related to the homegrown conditions and native design ethos. Just walking through Santiago one can see the impacts of contemporary Chilean architecture in buildings, campuses, interiors and stores. One can clearly argue that the build environment in Santiago have a stronger homegrown aroma than that same city had three, or four decades ago.

\section{DISGLOBAL JAPAN AND DISGLOBAL WORLD}

We can argue that other countries around the world experience similar processes. For example, in Japan the rise of a strong local architectural movement has coincided with a stronger sense of "Japanese-ness" in daily life. The works produced by small ateliers across that country such as Sou Fujimoto, Junya Ishigami, TNA, Yuko Nagayama, Hideyuki Nakayama, Studio Velocity, $\mathrm{O}+\mathrm{H}$ can only be traced to Japan's own architectural history, culture, and sensitivity. We can also observe this trend in some avant-garde movements in South Africa, Australia, Switzerland, and several countries in Latin America.

\section{OUR CONFERENCE}

In the "Cross-Americas: Probing Disglobal Networks" conference several ideas arose as a response to our call for papers. One of the strong themes that emerged from the presentations where those that questioned the relationship between architectural practice and architectural scholarship. In a number of presentations we saw a deep interest in addressing in the questions we posed for this conference from the singularity that provides the context of particular architectural or urban cases. The variety and diversity of contexts that we saw in the conference could lead us to two questions: Where could architectural thinking and academia fight its most important battles? And how should we evaluate the power of architecture as a discipline? 


\section{THE POWER OF ARCHITECTURE: SYNTHESIS}

Alejandro Aravena in his keynote intervention during the first day of the conference put into question Architectural power. He said he held the view that if architecture has one power, it is the power of synthesis. The power to reduce a very complex set of issues and restrictions into an inclusively particular answer. Aravena explained that for his practice this means to suspend any formal or design move until all the issues that "inform the form" are in full view. That means to somehow, be engaged with a certain level of critical pragmatism that can help us see the full forces present in an architectural case. This means to abandon ideological concerns and to focus with more intensity into the context condition and the circumstances of the project.

\section{THE POWER OF ARCHITECTURE: BASHO}

Another power of Architecture is its ability to generate place, topos, or locus. Japanese Philosopher Kitaro Nishida (1870 - 1945) argues that West and East organize space in a very different way. Nishida develops the notion he named the logic of place or the logic of "basho." Nishida reasons that "non-being is the metaphysical point of view that grounds Eastern culture, unlike Western culture which merely acknowledges 'something with form,' 'the formed,' or 'the determined' as 'reality.'" 5

Nishida thinks that Eastern reality is born from "absolute nothingness" and the idea of "form without a form," contrasting the dependence on form in the occidental construction of reality. Philosophers Kitaro Nishida and William James created the foundations of a post-Hegel tradition in philosophy. Foundations that improved on the notions of pure experience which was no longer dependent on the object-subject dualism that characterized the continental tradition of philosophy. Nishida's logic of "basho" can help us to see beyond formalism and to observe how our habits, behaviors, and experience construct our surroundings. It can ground us in our observations about how our reality is built with connections to homegrown cultures which intuitively shape place.

\section{THE POWER OF ARCHITECTURE: THE POWER OF NUMBERS}

A discussion about the power of architecture emerged in our conference in sessions that questioned what constitutes and what is architectural knowledge. One session in particular at the end of the conference titled "The Doctoral Credential, a New Reality?"

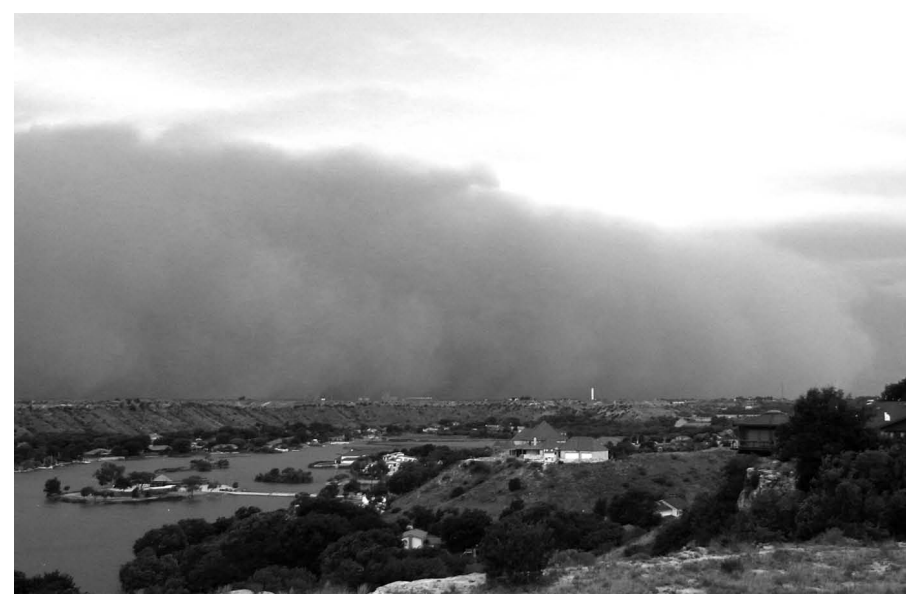

Figure: Coffee break at the Pontificia Universidad Católica de Chile, Escuela de Arquitectura. summarized comparisons of what constituted scholarship and the generation of knowledge in both sides of the Americas.

North American scholarship, especially those programs associated to doctoral degrees, seem to be associated to the more traditional notions of academic research that can be found in the STEM and humanities model in the U.S. and Canada. Can Architectural scholarship have a chance to impact traditional high-end research scholarship in North America?

Dean Mahesh Daas presentation showed that Architecture and Environmental Design programs produced only 118 doctorates in the United States in 2014 (up from 66 in 2004). This is equal to just $0.22 \%$ of all doctorates in the United States. Similarly Dean Daas showed that there are 5,834 faculty members in all NAAB accredited programs. Of those only 2,322 are full time faculty. And of those 2,322 full time faculty only 648 have doctoral degrees (28\%) and only 844 (36\%) have professional license. Dean Daas presentation show that the number of architectural doctoral graduates and faculty members are very low to influence the very high-end research community in the U.S. and Canada.

By contrast Emilio De La Cerda, Director of Universidad Católica de Chile, said that in their faculty and in general in the Chilean architectural schools there is a strong intention for architectural scholarship to also include architectural design. Some examples of design scholarship related to education in Chile can be found in the works of the Open City at Universidad Católica of Valparaiso, the Alejandro Aravena Elemental group that emerged at Universidad Católica de Chile, and the constructed thesis projects at the School at Architecture at Universidad of Talca. De La Cerda argued that the power of architecture as a discipline in Chile still resides in the particular impact architectural projects can have in the city and to lose the core of the profession in academic scholarship would mean a significant loss for the discipline.

\section{OUR CONFERENCE}

In our conference we saw how scholarship was engaged in wide range of particular home-grown contexts. The Architecture/Practice session reflected on the dissociative relationship between practice and education today. Several presentations gave insight about

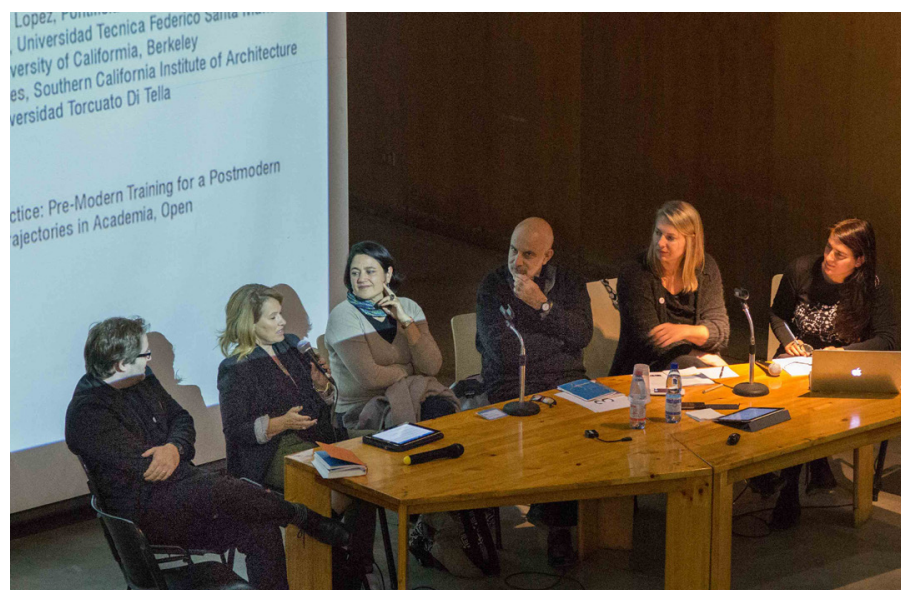

Figure: Panel session 


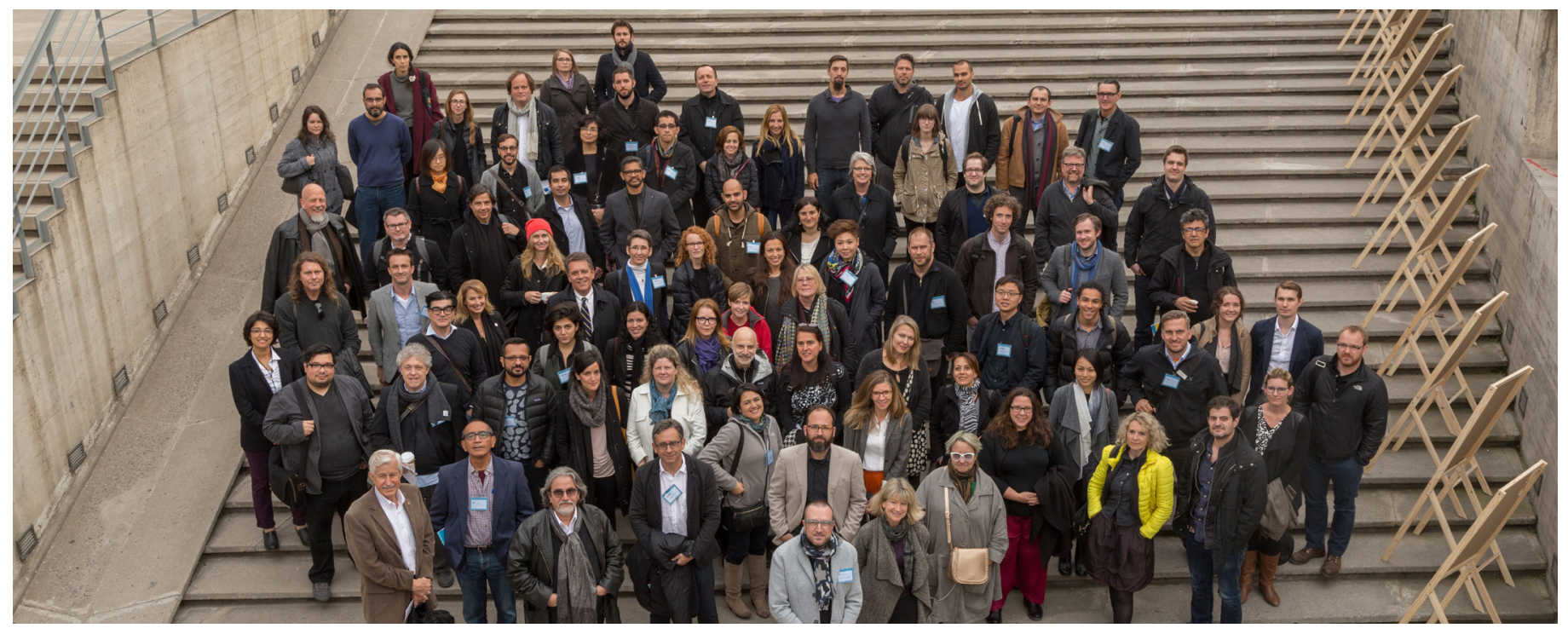

Figure: Conference attendees on the steps at Pontificia Universidad Católica de Chile, Escuela de Arquitectura

design-build experiences in which pedagogy is changed to respond to specific local conditions of craft (Talca, Nicaragua) and their possible relationship to to digital craft.

In the Cities/Urban Tactics session there was a strong interest in reinterpreting local conditions such as the super block public housing project in New York, open spaces in Belgrade, community spaces in old San Juan, water management in New Orleans, to urban ideas for Lynchburg Virginia. These works are contrasted with a more holistic scholarship that introduces architectural thinking about issues such as city security, public space, self-storage, city guides, and tools for participatory democracy. The wide range of entries in the Design Strategies session, although very diverse, raised common questions about how designers connect a wide variety of techniques, languages and world views to what the topic co-chairs call "working within the specific, situated processes and products of global systems." In the Ecology and New Trajectories in Academia sessions the discussions lead sometimes to themes that had global impact such as sustainability that are confronted to local cultures and methods.

\section{CONCLUSIONS}

Questioning of the concept of globalization helped us reveal a different reality. It allowed us to rethink where should architecture focus its forces. By examining and reflecting on education, scholarship, and critical practice from both sides of the hemispheres of the Americas helped us to come out from Santiago with a renewed faith in the importance of design scholarship and the impact that architectural synthesis can have in generating places or topos in our cities. Congresses that can help reveal a highly contextual design scholarship and practice will radically advance the agenda of our discipline. Thus, creating a more powerful and involved profession.

\section{ENDNOTES}

1 Krugman, Paul R. Pop internationalism. MIT Press, 1997.

2 Nobelprize.org. The Sveriges Riksbank Prize in Economic Sciences in Memory of Alfred Nobel, 2008, http://www.nobelprize.org/nobel_prizes nobelguide_eco.pdf. Accessed 23 Sep. 2016.

3 For example, China, the poster-child of globalization, is every year becoming less reliant on foreign trade. A decade ago, exports represented 37 percent of China's GDP but today exports make up just 22 percent of Chinese GDP, a trend that continues to shrink every year.

In America trade liberalization has killed manufacturing jobs but most of those job losses have come from workplaces becoming more efficient rather than international trade. Between 2000 and 2010 only $13 \%$ of job losses were related to trade while $87 \%$ of manufacturing employment losses were due to automation and more efficient factories. Hicks, Michael J., and Srikant Devaraj. "The myth and the reality of manufacturing in America." Center for Business and Economic Research, Ball State University (2015).

4 Koolhaas, Rem. "The generic City In: Koolhaas, Rem \& Mau, Bruce: S, M, L, XL." New York (1995).

5 Mayuko, Uehara. "Japanese Aspects of Nishida's Basho: Seeing the "Form without Form"." Fra Jobtager to Jobmager (2007). 